\title{
Effect of Cooling Agent on Temperature Profile During Molding Injection: Case Study for Polylactic Composites ${ }^{\#}$
}

\author{
RALUCA ISOPESCU, PAULA POSTELNICESCU* \\ University Politehnica of Bucharest, Department of Chemical and Biochemical Engineering, 1-7 Polizu Str., 011061, \\ Bucharest, Romania
}

\begin{abstract}
The paper presents a theoretical study for the cooling of polymer samples in an injection molding process. The study is applied for neat polylactic acid (PLA), PlA-talc and PLA-starch composite samples representing specimens for mechanical tests reported in literature. A one dimensional model was developed for the heat transport through the thickness of the sample from the polymer to the cooling agent: air in natural convection and water flowing through cooling channels. The heat of solidification of molten polymer was also considered. The model was solved in the frame of Matlab software. The results obtained consist in the evaluation of the final time required to reaches a temperature of about $60^{\circ} \mathrm{C}$ in the core of the specimen and the evaluation of the temperature profile along the cooling process. When using cooling air in natural convection the temperature profile shows insignificant space variation, but the duration of cooling is about 6 min. The use of cooling water proved to be more efficient in terms of cooling time is about 15-25s, while the temperature gradient in the thickness of the specimen is quite significant at any moment of time.
\end{abstract}

Keywords: injection molding, mold cooling, polylactic acid, composites

\section{Introduction}

Over the last decades, much attention has been given to the modeling and simulation of injection molding, due to its various applications in the range of processing technologies of plastic materials.

The interest of researchers in the fields of polymer science and chemical engineering for injection molding is determinate by the fact that this technology offers the possibility of producing articles with complex shapes and high dimensional precision at low cost [1], for domestic uses and industrial purposes, particularly in the automotive industry.

The injection molding is a complex cyclic process composed by a series of operations that are sequentially carried out in the injection machine: dosage of plastic pellets, melting, filling the cavity with melt polymer at an injection temperature, compression, cooling and ejection of the molded part.

The most studied stages of the cycle are the filling [2] and the compression [3], but also the cooling processes are intensively investigated based on experimental and theoretical studies [4]. For the characterization of the behavior of the injection molding machine, it is essential to simulate the heat transfer involved in each of these stages.

The cooling stage presents a great importance in this manufacturing technique, because it influences the quality of the produced articles by assuring that they become dimensionally stable before ejection. The heat transfer from the mold can be realized with air or liquids as water (commonly used), mixtures water-ethylene glycol or oil. The air assures a uniform cooling, but it requires a longer time for realizing the heat transfer, often inadequate for industrial production. In the case of liquids, the cooling agent circulates through a circuit of channels in the mold. The influences of the inlet temperature of the cooling agent, its flow regime and the cooling design were analyzed by many researchers. It was reported that the reduction of the inlet temperature of the cooling agent assures a short cooling time [5] and the difference between the inlet and the outlet temperature of the cooling agent should be between $1-3^{\circ} \mathrm{C}$ [6]. Regarding the flow regime of the coolant, a turbulent flow is recommended with a value of Reynolds number higher as 4,000 [6], preferably 10,000.

*email: p_postelnicescu@chim.upb.ro

\footnotetext{
\#This article is dedicated to the birth' centenary of Professor Raul Mihail, the founder of the Romanian School of Chemical and Biochemical Reactions Engineering
} 
The design of conformal cooling is very important because it has a great influence on the dimensional stability of the final product [7]. The traditional cooling circuits are represented by straight channels [8], but in many cases these types of channels do not follow the configuration of the article. Serial circuits and parallel circuits are often used in practice [6] and in each situation the design of the conformal cooling channels system may be accomplished for the desired configuration of the mold $[9,10]$. The mold cooling processes and also the solidification of the molten polymer was simulated on the basis of detailed mathematical models for heat transfer $[11,12]$. It was established that cooling system may assure uniform cooling in order to avoid defects such as residual stresses and shrinkage in the produced article $[13,14]$. In simulation of the cooling stage, the shrinkage behavior can be predicted by studying the variation of the specific volume with the temperature, based on the two-domain Tate equation of state for materials processed by injection molding [14]. Over the last decades, the engineers are engaged to develop methods for the intensification of the heat transfer [15]. The cooling efficiency of the injection molding machines was increased by using alternative cooling devices as bafflers, bubblers or thermal pins. The temperature distribution in the mold can be established by simulation of the heat transfer processes during the solidification and cooling of the molded components and it is used to characterize the uniformity of cooling [6,9]. It was reported that the cooling time represents above $75-85 \%$ of the cycle time [9], which is of the most important process parameter of the injection molding which influences the production throughput.

In the last years, scientists and producers in the field of synthetic polymers based on non-renewable crude oil and natural gas have identified severe problems as environmental pollution and overexploitation of fossil resources [16].

In these conditions, the production of polymers derived from renewable sources represents an excellent solution for today and for the future.

An alternative to the traditional plastics is represented by the biodegradable and biocompatible polymers [17]. Between the most promising biopolymers not only for packaging and textile industries, but also for medical applications, is the polylactic acid or polylactide (PLA) which is produced from annually renewable resources, as starch and sugar [1,17]. It is an aliphatic polyester, thermoplastic, ecofriendly, recyclable and compostable. PLA is characterized by good mechanical properties (high strength and stiffness), but also by law thermal stability, high moisture sensitivity and low solvents resistance $[17,18]$. PLA has a high cost by comparison with that corresponding to classic thermoplastic materials. Over the last years, PLA was used in composition of blends with other polymers and in composites with materials such as starch, cellulose and glass fibers [18, 19], with lower cost and adequate properties. The nanocomposites of PLA with inorganic or organic substances have numerous advantages regarding the mechanical properties and present an accelerated biodegradation $[1,20]$. PLA can be processed by many technologies (extrusion, injection molding, thermoforming, foaming, fiber spinning, 3-D printing), but a high number of products are realized by injection molding.

This paper presents a simulation study regarding the cooling process in the injection molding of PLA and composites of PLA with talc and corn starch. It was analyzed the temperature distribution in specimens for mechanical tests, with air and water as cooling agents and the cooling time for the considered compositions was calculated.

\section{Materials and methods}

\subsection{Selection of polymeric samples}

The thermal behavior during cooling in a molding machine was studied considering small flexural specimens made of polylactic acid and composites. The geometric sizes and main characteristics during thermal processing, such as melting point $\left(\mathrm{T}_{\mathrm{m}}\right)$, glass transition temperature $\left(\mathrm{T}_{\mathrm{g}}\right)$ and crystallinity, were taken from literature [22], and refer to neat PLA and PLA composites studied for automotive applications. The specimens had geometrical dimensions $(3.2 \mathrm{~mm} \mathrm{X} 12.6 \mathrm{~mm} \mathrm{X} \mathrm{125mm)} \mathrm{and} \mathrm{were}$ molded in a lab scale injection machine. 
The thermal modelling aimed to put into evidence the variation of temperature profile under slow cooling in air and rapid cooling using cold water. According to technical prescriptions, the polymer is injected in the mold at temperatures between $180-200^{\circ} \mathrm{C}$ and released when the temperature is below $60^{\circ} \mathrm{C}$.

\subsection{Mathematical model}

The mathematical model refers to the cooling period after the injection, when the heat is extracted ensuring the molten material to solidify, and then cool down to a prescribed temperature that enables the release of the material. Given small size of the specimens the only phenomenon considered was the unidirectional heat transfer, in the thickness of the sample, from the polymeric material to the environment.

During cooling, the heat may be taken directly by the surrounding air if no other cooling system is provided, as is the case in some lab size injection machines. If cooling agent is used, the heat is transferred mainly to the cooling agent that flows through the cooling channels. In this case, the heat transfer from the exterior surface of the mold to the environment may be disregarded as it is proved to be in a very small amount [21].

The temperature $(\mathrm{T})$ distribution in time, $\tau$, and the thickness of the specimen, $\mathrm{x}$, can be calculated using the equation:

$$
\rho \cdot c_{s} \frac{\partial T}{\partial \tau}=\frac{\partial}{\partial x}\left(k \frac{\partial T}{\partial x}\right)+q_{s}
$$

In (1), $\rho$ is the density, $k$ the thermal conductivity, $c_{\mathrm{s}}$ the specific heat of the polymer while $\mathrm{q}_{\mathrm{s}}$ stands for the heat generated rate during solidification.

Equation 1 can be solved numerically considering the boundary conditions that reflect the equality between the conductive flux in the polymer and convective flux to the cooling agent:

$$
-k \frac{\partial T}{\partial x}=h \cdot\left(T-T_{\text {cooling }}\right), \mathrm{x}=0, \mathrm{~L}
$$

$\mathrm{L}$ is the thickness of the specimen and $\mathrm{h}$ is the heat transfer coefficient through the mold wall the cooling agent boundary layer, calculated with relation:

$$
h=\frac{1}{\frac{\delta}{k_{\text {metal }}}+\frac{1}{\alpha}}
$$

In relation (3), $\delta$ is the thickness of the mold wall, $k_{\text {metal }}$ is the thermal conductivity of the mold wall and $\alpha$ is the heat transfer coefficient of air/water and, in relation (2), $T_{\text {cooling }}$ is the temperature of the cooling agent.

The generation rate is calculated considering the specific melting enthalpy of the polymer $\Delta \mathrm{H}_{\mathrm{m}}$.

$$
q_{s}=\frac{\rho \cdot \Delta H_{m}}{\Delta \tau_{s}}
$$

The duration of solidification process, $\Delta \tau_{\mathrm{s}}$ is calculated iteratively starting with assumed values for the time corresponding to the onset of solidification, $\tau_{\mathrm{s}, \mathrm{o}}$ and to the moment when all the material is solidified, $\tau_{\mathrm{s}, \mathrm{f}}$. The mathematical model is solved until convergence is reached: 


$$
\begin{aligned}
& \left|\tau_{s, o}^{k+1}-\tau_{s, o}^{k}\right|<\varepsilon \\
& \left|\tau_{s, f}^{k+1}-\tau_{s, f}^{k}\right|<\varepsilon
\end{aligned}
$$

The time for onset of solidification corresponds to the moment when on the boundary the melting temperature is attaint. The final time for the solidification step is considered when the temperature in the polymeric material dropped below the melting temperature all along the thickness of the specimen.

\section{Results and discussions}

\subsection{Samples physical properties}

Three distinct samples were considered, in terms of material composition. Some main properties are taken from an experimental study of PLA used in automotive applications [22] and are presented in Table 1.

Table 1. Main thermal properties of PLA and PLA composites

\begin{tabular}{|c|c|c|c|c|c|}
\hline & \multicolumn{5}{|c|}{ Property } \\
\hline Sample & Filler $(\mathrm{wt} \%)$ & $\mathrm{T}_{\mathrm{m}}\left({ }^{\circ} \mathrm{C}\right)$ & $\mathrm{T}_{\mathrm{g}}\left({ }^{\circ} \mathrm{C}\right)$ & Crystallinity $(\%)$ & $\Delta \mathrm{H}_{\mathrm{m}}(\mathrm{kJ} / \mathrm{kg})$ \\
\hline PLA & 0 & 172.3 & 63.0 & 3.6 & 20.9 \\
\hline PLA/Talc & 8.2 & 171.5 & 62.7 & 12.3 & 23.0 \\
\hline PLA/Starch & 9.7 & 171.5 & 60.8 & 15.4 & 24.0 \\
\hline
\end{tabular}

The melting enthalpy for $100 \%$ crystalline PLA is $93 \mathrm{~kJ} / \mathrm{kg}$ [22], but according to [23] it decreases with decreasing crystallinity.

The specific heat $(\mathrm{J} / \mathrm{kgK})$ for PLA is calculated using polynomial relations obtained by regression over o experimental data published in [24]:

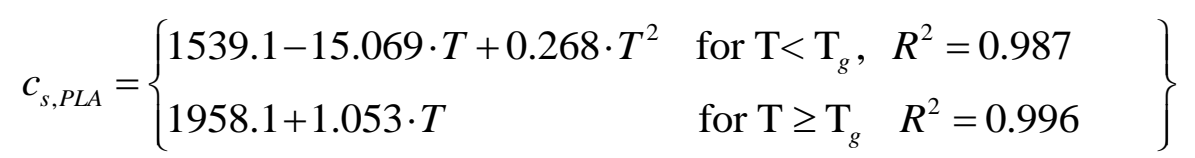

The thermal conductivity $k_{P L A}(\mathrm{~W} / \mathrm{mK})$ of neat PLA [25] varies with temperature, decreasing below the glass transition temperature.

$$
k_{P L A}=\left\{\begin{array}{ll}
0.111 & \text { for } \mathrm{T}<\mathrm{T}_{\mathrm{g}} \\
0.197 & \text { for } \mathrm{T}_{g}<T<T_{m} \\
0.205 & \text { for } \mathrm{T}>\mathrm{T}_{m}
\end{array}\right\}
$$

The molten PLA density is $1070 \mathrm{~kg} / \mathrm{m}^{3}$ and the density of solid PLA is $1252 \mathrm{~kg} / \mathrm{m}^{3}$.

The main physical properties of talc [26] and corn starch used as fillers in the studied samples are synthesized in Table 2.

Table 2. Main physical properties of the fillers

\begin{tabular}{|c|c|c|c|}
\hline \multirow{2}{*}{ Filler } & Density, $\left(\mathrm{kg} / \mathrm{m}^{3}\right)$ & $\begin{array}{c}\text { Property } \\
(\mathrm{J} / \mathrm{kgK})\end{array}$ & $\begin{array}{c}\text { Thermal conductivity } \\
(\mathrm{W} / \mathrm{mK})\end{array}$ \\
\hline Talc & 2580 & 852 & 7.01 \\
\hdashline Starch & 620 & 2750 & 2.16 \\
\hline
\end{tabular}

The physical properties of the composites were calculated using conventional mediation formula as function of composition. 


\subsection{Simulation results}

For all three samples the heat transfer was simulated considering two distinct cooling conditions: (i) cooling in air considered in natural convection (heat transfer coefficient $10 \mathrm{~W} / \mathrm{m}^{2} \mathrm{~K}$ ) at $22^{\circ} \mathrm{C}$ and (ii) cooling water ensuring a heat transfer coefficient of $800 \mathrm{~W} / \mathrm{m}^{2} \mathrm{~K}$, reasonable for a lab scale molding machine. The mean temperature of water is $25^{\circ} \mathrm{C}$ The wall of the mold is considered $15 \mathrm{~mm}$ thick [7] and is built of steel with thermal conductivity $k_{\text {metal }}=42 \mathrm{~W} / \mathrm{mK}$.

\subsubsection{Temperature profiles for neat PLA and PLA composite samples}

The mathematical model for air / water cooling systems was solved in the frame of Matlab (Natick, MA, USA) software using the built-in function pdepe, defined for initial-boundary value problems for unidimensional partial derivative equations. A discretization using 80-space and 100-time nodes was used. The variation of temperature in the thickness of the samples was obtained, together with information regarding the period of time in which the solidification occurs and also the final time $\left(\tau_{\text {final }}\right)$ necessary to reach a temperature of $60^{\circ} \mathrm{C}$ in the core of the sample. The data referring to the cooling process evolution are presented in Table 3.

Table 3. Main data for the cooling of PLA and PLA composites specimens

\begin{tabular}{|c|c|c|c|c|c|}
\hline Sample & Cooling agent & $\tau_{\mathrm{s}, \mathrm{o}}(\mathrm{s})$ & $\tau_{\mathrm{s}, \mathrm{f}}(\mathrm{s})$ & $\tau_{\text {final }}(\mathrm{s})$ & $\begin{array}{c}\text { Sample core final } \\
\text { temperature }(\mathrm{C})\end{array}$ \\
\hline \multirow{2}{*}{ PLA } & air, natural convection & 2 & 19 & 150 & 60 \\
\cline { 2 - 5 } & water & 0.5 & 4 & 25 & 62 \\
\hline \multirow{2}{*}{ PLA/Talc } & air, natural convection & 18 & 38 & 300 & 60 \\
\cline { 2 - 6 } & water & 0.5 & 2.4 & 13 & 61 \\
\hline \multirow{2}{*}{ PLA/Starch } & air, natural convection & 17 & 30 & 350 & 60 \\
\cline { 2 - 6 } & water & 0.5 & 3 & 15 & 61 \\
\hline
\end{tabular}

Data in Table 3 show that when the mold is simply placed in air the cooling time is long, up to 6 min for the PLA/Starch composite.

If cooling water is used cooling times are much shorter. The value of the final time calculated for PLA is in accordance with other results reported in experimental researches for similar PLA specimens [16].

Figure 1 presents the temperature profiles all along the cooling process using air in natural convection.

A good visualization of the temperature gradient in the thickness of the specimens is given by Figure 1 (b, d, f) where the temperature gradient at some moments of time can be easily noticed. Higher differences in temperature between the center and the borders of the specimen are noticed for neat PLA, where at $30 \mathrm{~s}$ this difference is $20^{\circ} \mathrm{C}$. For composite materials the temperature gradients are negligible.

The very small temperature gradient is explained by the ratio between the thermal resistance in the polymeric material and in the air in natural convection. The Biot number, relation (9) is a simple way of evaluating this relative difference:

$$
B i=\frac{h}{k} L
$$




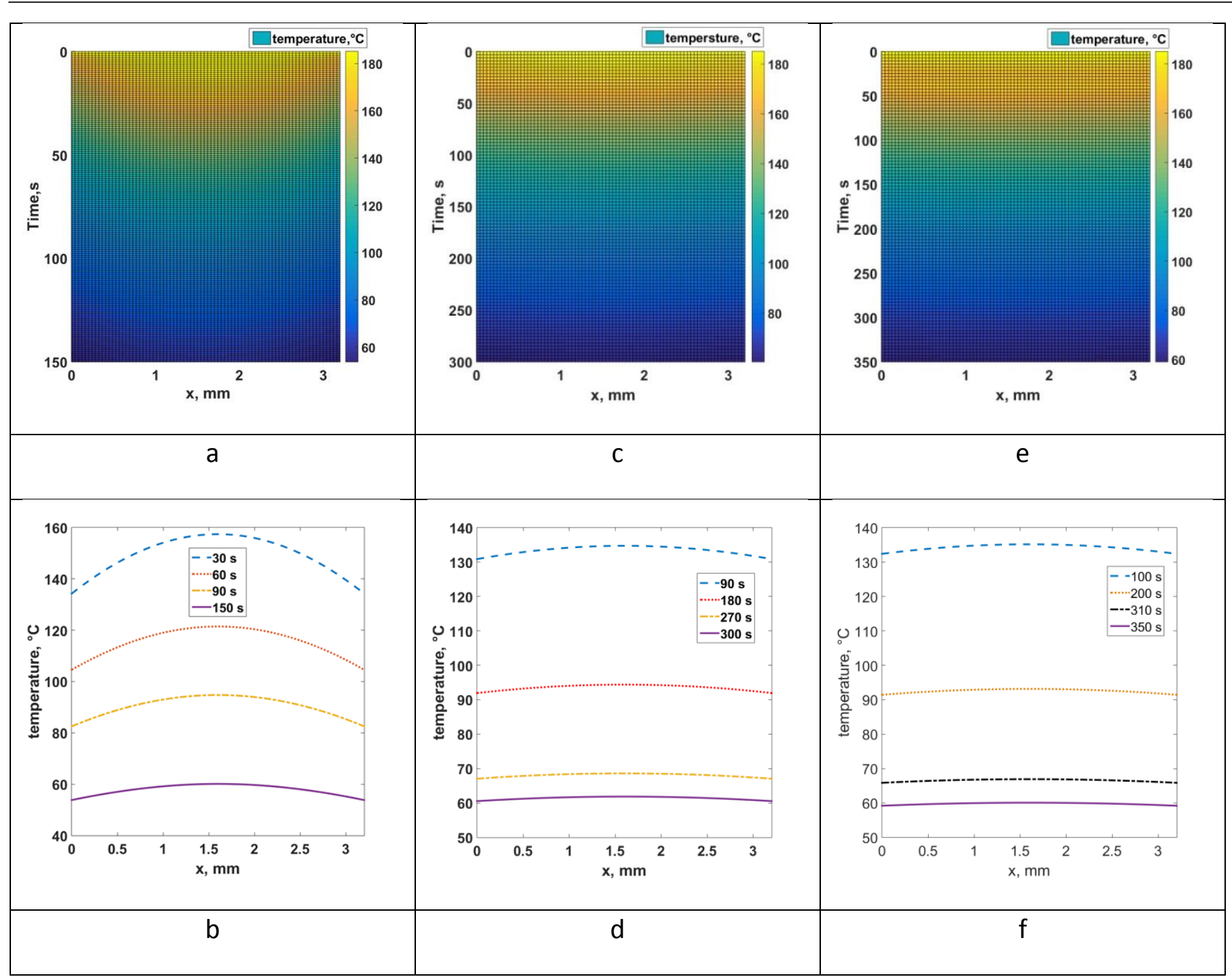

Figure 1. Temperature profiles for studied samples cooled in air: a, b- neat PLA; c, d-PLA/Talc; e, f -PLA/Starch

In relation (9), $\mathrm{L}$ is the characteristic length, considered as the distance between the center of the specimen and the wall of the mold $(\mathrm{L}=3.2 / 2 \mathrm{~mm})$. The mean thermal conductivity $(\mathrm{k})$ of the samples varies from $0.19 \mathrm{~W} / \mathrm{mK}$ for neat PLA to $0.45 \mathrm{~W} / \mathrm{mK}$ and $0.55 \mathrm{~W} / \mathrm{mK}$ for PLA/Talc and PLA/Starch respectively. The heat transfer coefficient $(\mathrm{h})$ for air in natural convection has low values, $10 \mathrm{~W} / \mathrm{m}^{2} \mathrm{~K}$ and small Biot numbers are realized, $\mathrm{Bi}<<1$. In these cases, small temperature gradients are expected in the solid layer. The increasing $\mathrm{k}$ values for composites leads to smaller Biot numbers compared to neat PLA and, consequently even smaller temperature gradients are noticed, but longer cooling duration. A constant temperature profile during cooling is generally recommended to overcome differential shrinkage of the material. The disadvantage of air cooling is the longer time required.

Figure 2 presents the temperature profiles resulted when cooling water is used. 


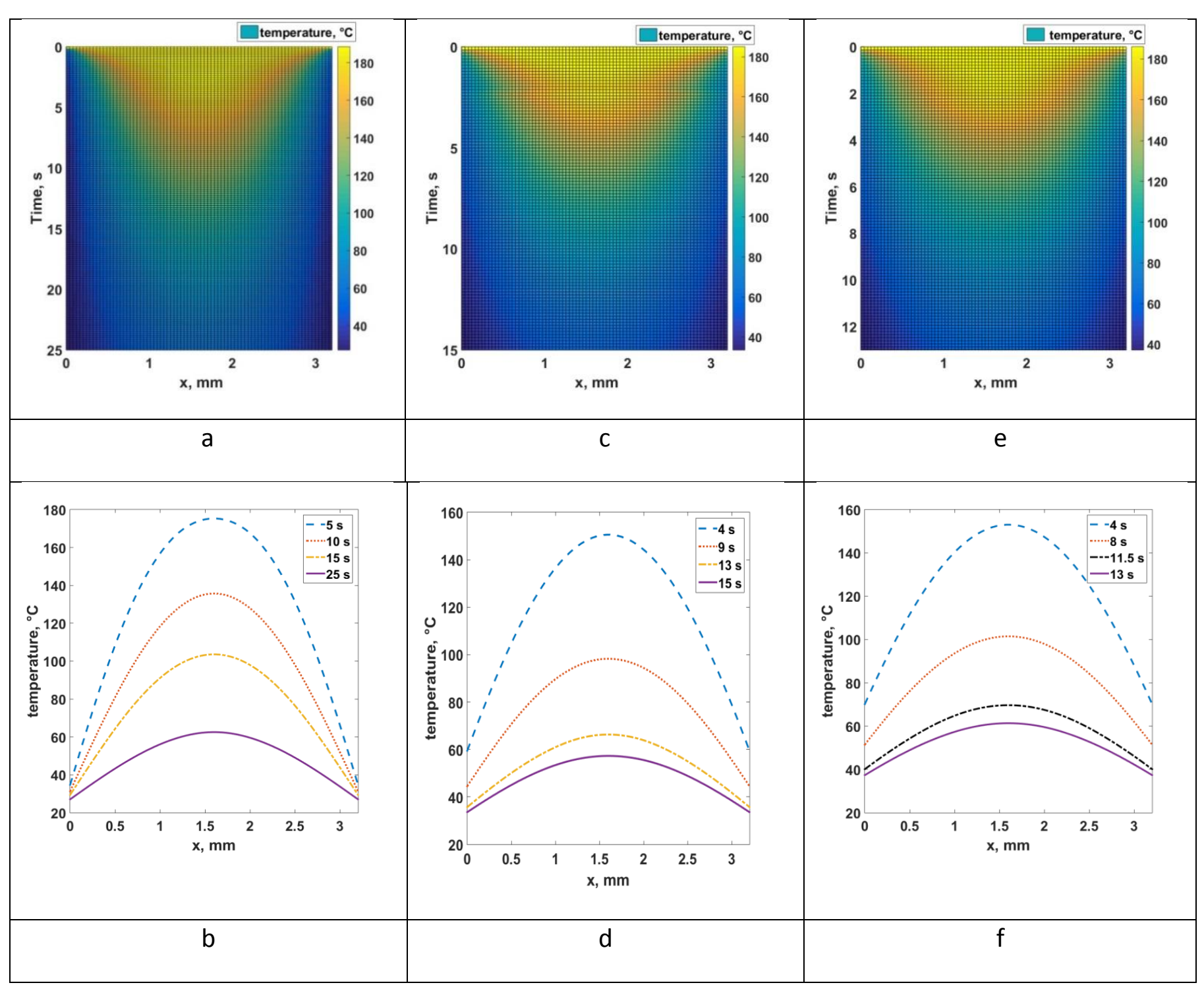

Figure 2. Temperature profiles for studied samples using cooling water: a, b- neat PLA; c, d-PLA/Talk; e, f -PLA/Starch

For cooling water the time until final prescribed temperature is much shorter, under $1 \mathrm{~min}$, and decreases in the order PLA, PLA/Talc, PLA/Starch. This is quite expected as the thermal conductivity and thermal diffusivity is higher for PLA composites. The high convective heat transport coefficient ensures a rapid take of the heat released by the solidification of the sample but also leads to important temperature gradients in the specimen.

As can be seen from Figure 2, the temperature gradient is high along the process: during the first $5 \mathrm{~s}$ of the cooling step a difference of temperature between the center and the borders of the sample is in the range of $80-100^{\circ} \mathrm{C}$. In this case, important processes, such as solidification and glass transition occur simultaneously in different points in the sample thickness. This is generally regarded as a disadvantage because it can lead to defects in the final product. Taking into consideration the small size of the considered specimen, the drastic time reduction may be more important than the uniform temperature profile and recommend the use of cooling water

\section{Conclusions}

The studied cooling conditions for neat PLA and PLA composites during injection molding enabled the evaluation of cooling time and temperature profile that are much influenced by the polymer composition and cooling agent use. Even for the small specimens considered, where a simplified one- 
dimensional model was used, the results proved that mathematical modelling can bring good information for practical applications. Cooling in air at natural convection can ensure a very steady temperature profile but increases significantly the time required to reach a low temperature of the specimen.

\section{References}

1.LIM, L.T., AURAS, R., RUBINO, M., Processing technologies for poly (lactic acid), Prog. Polym. Sci., 33, 2008, 820-852.

2.HAN, C.D., Rheology and processing of polymeric material, vol.2: Polymer processing, Oxford University Press, 2007, 358-375.

3.MIHAIL, R., STEFAN, AL., Simularea proceselor de formare a polimerilor, Editura Tehnică, Bucuresti, 1989, 264-269.

4.TADMOR, Z., GOGOS, C. G., Principles of polymer processing, $2^{\text {nd }}$ ed., John Wiley \& Sons, 2006, 791-793.

5.YEMENICI, O., ARDAGUNEY, A., An analysis of cooling time in plastic injection molding with influence of inlet temperature of cooling fluid, IJMP, 4(6), 2016, 76-79.

6.MARQUES, S., SOUZA, A. F., MIRANDA, J., YADROITSAU, I., Design of conformal cooling for plastic injection molding by heat transfer simulation, Polimeros, 25(6), 2015, 564-574.

http://dx.doi.org/10.1590/0104-1428.2047

7.SERES,, I., Injectarea materialelor termoplastice, Editura Imprimeriei de Vest Oradea, 1996, 417-431. 8.KHAN, M., AFAQ, K., KHAN, U.N., AHMAD, S., Cycle time reduction in injection molding process by selection of robust cooling channel design, ISRN Mechanical Engineering, 2014, Article ID 968484, 1-8. http://dx.doi.org/10.1155/2014/968484

9.PRASETIYO, A.B., FAUZUN, F., Numerical study of cooling channel configuration and size of the product cooling effectiveness in the plastic injection molding, MATEC Web of Conferences 197, 08019, AASEC 2018. https://doi.org/10.1051/matecconf/201819708019

10.DIMLA, D. E., CAMILOTTO, M., MIANI, F., Design and optimization of conformal cooling channels in injection molding tools, J. Mater. Proc. Technol., 164-165, 2005, 1294-1300.

doi: 10.1016/j.jmatprotec.2005.02.162

11.ASHA, S., ADEMOLA, E., IBEMERE, N., P., IFEANYI, C.O., IMOH, U.R., Parametric analysis of an injection molding system performance for PET products production, Sch. J. Eng. Tech., 4(9), 2016, 441-458. doi: 10.21276/sjet.2016.4.9.8

12.HASSAN, H., REGNIER, N., LEBOT, C., PUJOS, C., DEFAYE, G., Effect of cooling system on the polymer temperature and solidification during injection molding, Appl. Therm. Eng., 29 (8-9), 2009, 1786. doi: 10.1016/j.applthermaleng.2008.08.011

13.WENHE, D., Bin, Y., RU, X., LIFEN, S., JIBIN, M., JIASHENG, Q., PENG, C., XUECHANG, Y., QIANLEI, Z., SHUANGKUAN, D., Three-dimensional simulation of shrinkage behavior of injectionmolded poly lactic acid (PLA): effect of temperature, shear rate and part thickness, J. Res. Updates Polym. Sci., 2, 2013, 168-173. http://dx.doi.org/10.6000/1929-5995.2013.02.03.4

14.WANG, J., HOPMANN, C., SCHMITZ, M., HOHLWECK, T., WIPPERFURTH, J., Modeling of pvT behavior of semi-crystalline polymers based on two-domain Tate equation of state for injection molding, Mater. Des., 183, 2019, 108149.

15.DANCIU, E., LAVRIC, E.D., BELCHITA, E., Studiul experimental privind intensificarea transferului termic utilizând curgerea prin minicanale elicoidale, Rev. Chim., 51(2), 1999, 145-149.

16.HAMAD, K., KASEEM, M., DERY, F., Melt rheology of poly (lactic acid) low density polyethylene polymer blends, ACES, 1, 2011, 208-214. DOI:10.4236/aces.2011.14030

17.FARAH, S., ANDERSON, G.D., LANGER, R., Physical and mechanical properties of PLA and their functions in widerspread applications - a comprehensive review, Adv. Drug Deliv. Rev., 2016. http://dx.doi.org/10.1016/j.addr.2016.06.012

18.GARLOTTA, D., A literature review of poly (lactic acid), J Polym Env., 9(2), 2002, 63-84. 
19.HUDA, M. S., DRZAL, L.T., MOHANTY, A. K., MISRA, M., Chopped glass and recycled newspaper as reinforcement fibers in injection molded poly (lactic acid) composites: a comparative study, Compos Sci Technol., 66, 2006, 1813-1824.

20.MiSTRETTA, M, C, BOTTA, L., MORREALE, M., RIFICI, S., CERAULO, M., LA MANTIA, F.P., Injection molding and mechanical properties of bio-based polymer nanocomposites, Materials, 11, 2018, 613. doi:10.3390/ma11040613

21.PARK, S.J., KWON T.H., Optimal cooling system design for the injection molding process, Polym. Eng. Sci., 38(9), 1998. 1450-1462

22.HARRIS, A.M, LEE, E.C., Injection molded polylactic (PLA) composites for automotive applications, Proceedings of the $6^{\text {th }}$ Annual Meeting SPE Automotive Composites Conference, Michigan, USA, 12-14 sept, 2006, p.1-9.

23.TÁBI, T, SAJÓ I.E., SZABÓ, F., Luyt, A.S., KOVÁCS, J.G. Crystalline structure of annealed polylactic acid and its relation to processing, Expres Polym. Lett. 4(10), 2010, 659-668.

24.PYDA, M., BOPP, R., WUNDERLICH, B., Heat capacity of polylactic acid, J. Chem. Thermodyn., 36(9), 2004, 731-742.

25.SIN, L.T., AHMAT, A.R., RAHMAN, W.A.W.A., Polylactic acid: PLA Biopolymer Tehnology and Application, Elsevier Inc, 2013, 132-135.

26.YONEDA, A., YONEHARA, M., OSAKO, M., Anisotropic thermal properties of talc under high temperature and pressure, Phys. Earth Planet. Inter, 190-191, 2012, 10-14.

Manuscript received: 15.01.2021 